\title{
A Framework for implementing value- based approach in Asset Management
}

\author{
Irene Roda', Ajith Kumar Parlikad², Marco Macchi ${ }^{3}$, Marco Garetti ${ }^{3}$
}

Abstract ISO 55000 puts 'value' at the core of asset management. This paper provides a framework to help production companies implement value-based Asset Management (AM) in a way that it contributes to operational excellence. Valuebased AM is achieved when the value delivered by assets is used by the organization as the key decision criterion to choose between different AM options (both at tactical and operational level). Given this perspective, it is vital that organizations are able to quantify the value delivered by their assets and manage that value through informed and coherent decision-making. Value-based AM is still a concept more quoted in theory than described in practical terms. A clear understanding about the main elements that are needed to enable it is still missing in industrial practice. The framework presented in this paper provides the key elements needed for successful integration of a value quantification model with the AM system to ensure the effective implementation of value-based approach in AM.

\section{Introduction}

Asset Management (AM) is a value-adding process to the core business of an organis ation and should be considered so by companies (Liyanage \& Kumar 2003; Amadi-Echendu et al. 2010; El-Akruti et al. 2013; ISO 55000:2014(E) 2014). Indeed, AM has a key role in strategy development and implementation. This strategic role is maintained based on planning and control of the asset-related activities (ElAkruti et al. 2013).

As stated in the ISO5500x series of standards on AM (released on January 2014), the concept of value is at the heart of Asset Management. AM is in fact defined as the coordinated activity of an organization to realize value from assets

\footnotetext{
${ }^{1}$ I. Roda $(\bowtie)$

Dept. of Management, Economics and Industrial Engineering, Politecnico di Milano, Italy e-mail: irene.roda@polimi.it

${ }^{2}$ A. K. Parlikad

Institute for Manufacturing, University of Cambridge, UK

email: $\underline{\text { aknp2@cam.ac.uk }}$

${ }^{3}$ M. Macchi, M. Garetti

Dept. of Management, Economics and Industrial Engineering, Politecnico di Milano, Italy
} 
(ISO 55000:2014(E) 2014). Value is obtained through providing assets that allow an organization to fulfil its strategic intent (El-Akruti \& Dwight 2013). No single detailed definition of 'value' delivered by assets can be found in the literature. In fact, its specific definition is very much dependent on the company's purpose, the nature of its assets, its objectives and the expectations of its stakeholders. It can be tangible or intangible, financial or non-financial (ISO 55000:2014(E) 2014). What is agreed is that the realization of value involves balancing costs, risks, opportunities and benefits arising from the way assets are specified, procured, deployed, used, maintained and disposed. Each company has to define its own conception of value, given the specific context in which it operates. Despite the increasing body of academic literature and industrial interest on AM process and systems and the strategic role of AM (El-Akruti et al. 2013), value-based AM is still a concept much more quoted in theory than described in practical terms. A clear understanding within companies about the key elements needed to enable it is still required. The assumption is that value-based AM is achieved when the value delivered by assets is used as the decision criterion to choose among different AM options (both at tactical and operational level). The aim of this paper is to provide a framework that drives production companies towards the implementation of value-based AM contributing to operations excellence.

\section{Value-based AM Framework}

The idea that proper lifecycle management of physical assets is an essentialactivity to contribute to the value delivered by an organization is becoming more widely accepted nowadays. The AM perspective is set on the management of an asset in a way to create and/or sustain value during each life-cycle stage, and throughout the asset's life. Therefore, to ensure value-based AM, it is important that value delivered by assets along its life cycle is used as the decision criterion to choose among various AM options. Hence, a model able to quantify such value is required. The "value-model" is intended to be used whenever an AM decision has to be taken. Several value-models have been proposed so far depending on the specific interpretation given to value in different contexts (e.g. Total Cost of Ownership (Roda \& Garetti 2015), Value Mapping (Srinivasan et al., 2015). Figure 1 shows how the value-model sits within the AM System.

The expected main functions of the value-model are:

- To enable and control AM planning and implementation by supporting decision making and options / scenario analysis;

- To support communication of asset value contribution internally and externally to the organization enhancing commitment and continuous improvement;

- To controlalignment between the AM plans and operations and the AM strategy. 
This paperaims at providing a vision of the key elements needed for a successful integration of a value-model with the AMS to ensure the effective implementation of value-based approach in AM.

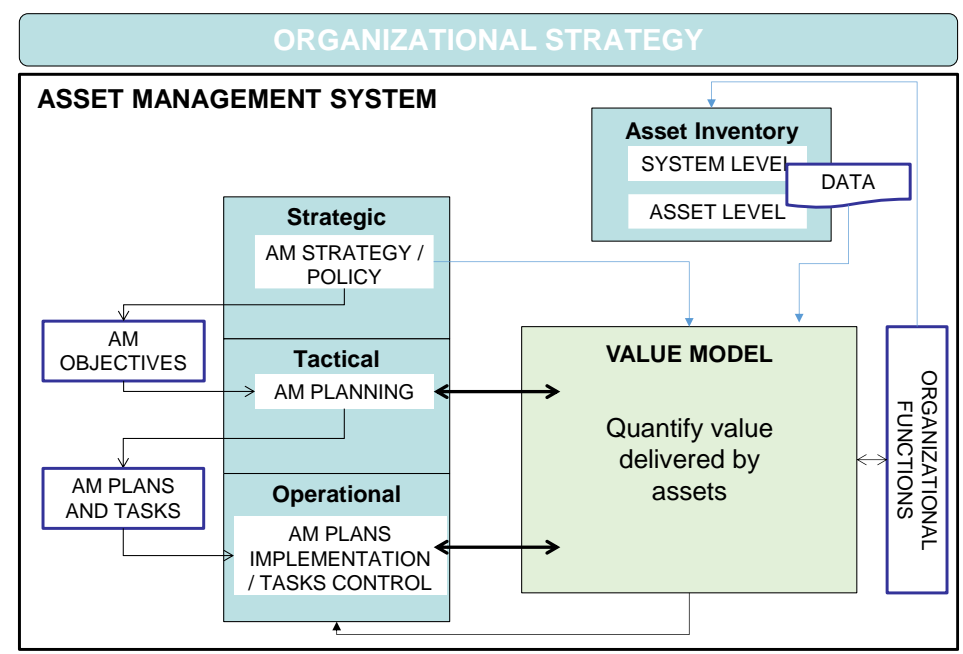

Figure 1. The value-model integrated in the AM System

Our research reveals that there are some key elements needed to ensure proper value-based decision making in general for any company, independent of the definition given to value. Those key elements have been categorized and outlined within a framework as shown in Figure 2. The framework was depicted in line with the IDEF0 standard. The seven key elements are represented under the following categories - control factors, inputs and resources - in the context of the asset value model. We will now describe each of these in detail in the next section.

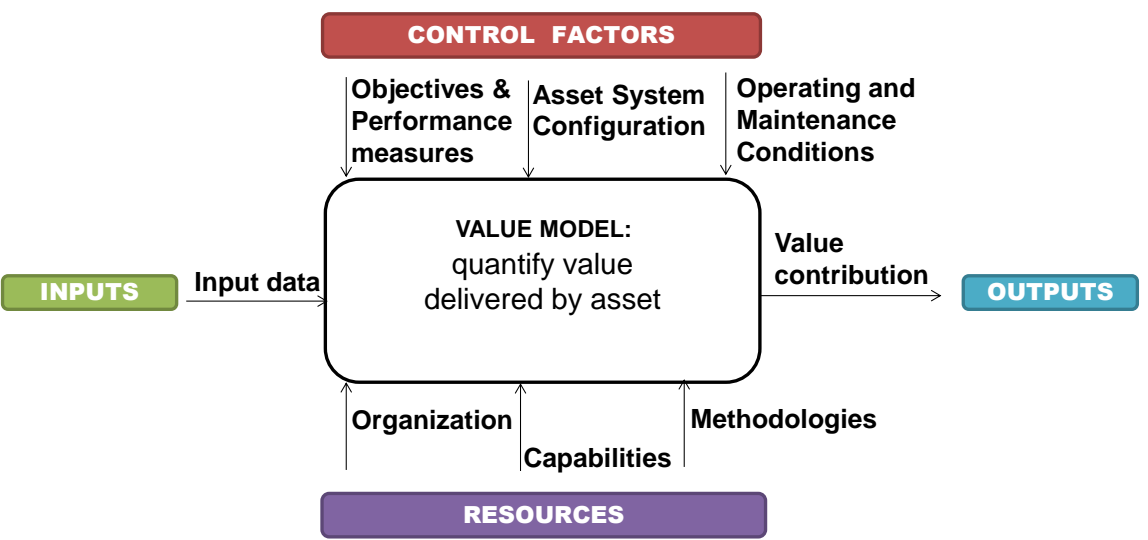

Figure 2 Value-based Asset Management framework 


\section{Key elements of value-based AM}

\subsection{Control factors}

Control factors are the conditions to the value-model affecting the outputs.

\section{Objectives and performance measures}

As stated in ISO55000, AM involves the balancing of costs, opportunities and risks against the desired performance of assets, to achieve the organizational objectives. Therefore, the first requirement for proper value-based AM implementation is that AM objectives are clearly identified and that they are SMART (Specific, Measurable, Achievable, Realistic and Timely) and aligned with the organizational objectives. Alignment should exist between the company's fundamental strategic objectives (what the company wants to be), the plant-specific strategic objectives (what the company aims in operating the plant) and the AM objectives (what is the aim of the company in managing the production assets) (Liyanage \& Kumar 2003). The overall alignment should be checked periodically to ensure that the value-model is actually based on the value drivers of the company (may it be for example profit, environmental impact, safety, customer satis faction, etc.).

In addition, the organization (or its AM function) needs to identify the desired performance targets and measures for each asset as well as for the AM system (Wang et al., 2015). The AMS performance measures need to encompass technical (at system level and equipment level), economical and organizational dimensions reflecting the holistic characteristic of AM.

\section{Asset System Configuration}

An asset system such as a production plant must be viewed as a collection of assets that interact, and interdependencies between the as sets can affect the systemic value contribution. For instance, interdependencies imply that failure/deterioration of any asset within the systemcan have knock-on effects throughout the systemand might create additional costs or risks, and this might not be clear when managing each asset independently.

While individual asset-level analysis estimates performances with respect to a single component (OEE is the performance measure best representing this concept), system-level analysis allows considering systemic value contribution arising from components' interdependencies (Xu et al. 2013; Liang, Z. \&Parlikad, A.K 2015ab). Depending on the objectives and the AM KPIs and value drivers, specific kinds of interdependencies are to be considered in order to evaluate the value contribution of a local intervention at the system level. Possible kinds of interdependencies among assets can be economic, stochastic and structural dependencies (Nicolai \& Dekker 2008), and functional - logical interdependency (as sets jointly contribute to the delivery of a function as required). In most cases, a subset of interdependencies are modelled depending on the problem at hand, and the resources the organization wants to spend on modelling. This is essential to strike the right balance between modelling complexity and accuracy. It is essential to use a reasonable model of the system to control and influence the value-model's output. 


\section{Ope rating conditions \& Maintenance}

Different operating conditions and maintenance management policies affect the level of value provided by the assets. Operating conditions include the specific function executed by the system, the environment in which it works, the available working time for it to produce etc. In any of these cases, it is clear that in the event of a change, that influences the value contribution realized by the system, hence the value-model should integrate it. The same is valid for maintenance policies implemented in the system. For example, the execution of pure corrective maintenance or the implementation of preventive and predictive maintenance directly affect the way the system can generate value. It is then essential to ensure that these control factors are integrated in a value-model that is used to support decision-making. It allows setting the proper operating condition and maintenance activities to increase value contribution, given the AM objectives.

\subsection{Inputs}

Inputs are the data transformed/consumed by the value-model to produce outputs.

\section{Input data}

Data is a critical asset in today's organizations (Borek et al. 2014) and the availability of useful data is paramount to making the best decision in AM. Bringing all of disparate data together into widespread asset-centric information is yet a key challenge facing asset users today; an integrated asset information management strategy would be required (Ouertani et al. 2008). When considering which data are needed for supporting informed AM decision making, it must be taken into account that the data that are required can vary from case to case depending on the definition given to value. What is generally recognized is that both technical and financial data are needed. The major challenge in obtaining the required data is that they are heterogeneous, hence they are usually scattered among separate information systems (administrative IT systems, industrial IT and non-automatic sources) (Moore \& Starr 2006; Kans \& Ingwald 2008). May it be at IT level or not, it is widely agreed that integration must facilitate the bi-directional flow of data and information into the decision-making at all levels (Moore \& Starr 2006). The core idea is that, a common asset database should be developed where for each asset, at different aggregation level different data can be stored all together. The asset database would provide basic reference to information regarding assets' properties for strategic decisions (Kans \& Ingwald 2008; Tam \& Price 2008).

Data quality is also a critical aspect to consider to ensure proper decision-making. The first step towards high quality data for any organisation is the Data Quality (DQ) assessment (more information on this can be found in (Borek et al. 2014)).

\subsection{Resources}

Resources are the means that support the execution of the value-model. 


\section{Organization}

The application of the value-based AM concept in a company calls for an organizational architecture and culture that promote the concept of whole-life value-based system-wide as set management and its reception as an effective process (Liyanage \& Kumar 2003). Different organizational functions are involved in the AM process with their specific role in the organization's structure. In order to integrate AM in a company as a single process, two main requirements should be complied: (i) integration among different organizational functions that contribute in the AM valuechain; (ii) clear definition of AM related roles, authority and responsibilities .

The first thing to be considered is the interdisciplinary and collaborative nature of the AM system that can be gleaned from the definition of asset life cycle from a userviewpoint itself (El-Akruti \& Dwight 2013). At each life cycle stage of an as set, different disciplines and hence different organizational functions are needed. The success of a capital intensive organization often depends on its ability to coordinate activities efficiently and effectively among the various asset-related activities (ElAkruti \& Dwight 2013).

Secondly, as it is stated in the ISO55000 as well, leadership and workplace culture are determinants of realization of value and this includes clearly defined roles, responsibilities and authorities. It is advocated that the existing organization roles involved in asset management value chain are modified to include AM responsibilities and accountabilities. One ramification for this is that conventional process control rooms may need to be converted into ownership, management, and utilization centres (Amadi-Echendu 2004).

\section{Capabilities}

Capability is the measure of capacity and the ability of an entity (system, person or organization) to achieve its objectives. In order to implement value-based AM, certain capabilities are needed in an organization. AM capabilities include processes, competences and technologies to enable the effective and efficient development and delivery of AM plans and as set life activities, and their continual improvement (ISO55000). It is important for a company to put effort to foster them. Regarding required AM competencies, given by the ability to apply knowledge and skills to achieve intended results, details can be found in the IAM report (Competence Framework, 2008). Concerning the required technologies, a reliable and flexible IT system should be integrated allowing the use of an asset common database and the implementation of the needed AM process activities (see (Koronios et al. 2006). Proper DDSs need to be adopted as well.

\section{Methodologies}

Companies need to use specific methodologies to set the value-model and integrate it as a support in decision-making. Different methodologies will be required depending on the specific case. Some examples are: Root Cause Analysis (RCA), FMEA, etc., that help identifying criticalities and defining the reference system model. Moreover, methodologies such as data analytics methods, RAM analysis and risk evaluation approaches should be integral part of the AM approach. 


\subsection{Outputs}

The envisioned output of the value-model is the quantification of value delivered by assets and it is the criterion guiding the decision-making.

\section{Conclusions and future research}

In the paper, a framework has been proposed highlighting and categorizing the key elements to be considered to enable the integration of a value-model with the AMS ensuring the effective implementation of value-based approach in AM in production companies. In fact, value-based AM is implemented when the value delivered by assets is taken as the decision criterion whenever a decision about assets must be taken (at operational or tactical level). The framework is addressed to the decision makers in the company to support them ensuring that they take informed decisions contributing to value generation.

\section{Acknowledgments}

The research work was performed within the context of Sustain-Owner ("Sustainable Design and Management of Industrial Assets through Total Value and Cost of Ownership"), a project sponsored by the EU Framework Programme Horizon 2020, MSCA-RISE-2014: Marie Skłodowska-Curie Research and Innovation Staff Exchange (RISE) (grant agreement number 645733 - Sustain-Owner - H2020MSCA-RISE-2014)

\section{References}

Amadi-Echendu, J., 2004. Managing physical assets is a paradigm shift from maintenance. In Engineering Management Conference, pp 1156-1160.

Amadi-Echendu, J., Willett, R. \& Brown, K., 2010. What is engineering asset management? In Definitions, Concepts and Scope of Engineering Asset Management. Springer London, pp. 3-16

Borek, A. et al., 2014. A risk based model for quantifying the impact of information quality. Computers in Industry, 65(2), pp.354-366.

El-Akruti, K., Dwight, R.,Zhang, T., 2013. The strategic role of Engineering Asset Management. International Journal of Production Economics, 146(1), 227-239.

IAM, 2008. The IAM Competences Framework (November).

ISO 55000:2014(E)Asset management - Overview, principles and terminology

Kans, M. \& Ingwald, A., 2008. Common database for cost-effective improvement of maintenance performance. International Journal of Production Economics, 113, pp.734-747. 
Koronios, A., Lin, S. \& Gao, J., 2006. A Data Quality Model for Asset Management in Engineering Organisations. International Conference on Information Quality (MIT IQ Conference), p.25.

Kumar, U. et al., 2013. Maintenance performance metrics: a state of the art review, Journal of Quality in Maintenance Engineering, 19(3), pp.233-277.

Liang, Z., Parlikad, A.K., 2015a. A condition-based maintenance model for as sets with accelerated deterioration due to fault propagation, IEEE Transactions on Reliability (Article in Press)

Liang, Z., Parlikad, A.K., 2015b. A tiered modelling approach for condition based mainte-nance of industrial as sets with load sharing interaction and fault propagation. IMA Journal of Management Mathematics, Volume 26, Issue 2, 125-144.

Liyanage, J.P. \& Kumar, U., 2003. Towards a value-based view on operations and maintenance performance management. Journal of Quality in Maintenance Engineering, 9(4), pp.333-350.

Moore, W.J. \& Starr, a. G., 2006. An intelligent maintenance systemfor continuous cost-based prioritisation of maintenance activities. Computers in Industry, 57(6), pp.595-606.

Murthy, D.N.P., Atrens, A. \& Eccleston, J.A., 2002. Strategic maintenance management. Journal of Quality in Maintenance Engineering, 8(4), pp.287 - 305.

Nicolai R. P., Dekker R., 2008. Optimal Maintenance of Multi-component Systems: A Review. In Complex System Maintenance Handbook, London, Springer.

Ouertani, M., Parlikad, A. \& McFarlane, D., 2008. Towards an approach to Select an Asset Information Management Strategy. IJCSA, 5(3), pp.25-44.

Roda, I., and Garetti M., 2015. Application of a Performance-driven Total Cost of Ownership (TCO) Evaluation Model for Physical Asset Management. In 9th WCEAM Research Papers, pp. 11-23. Springer International Publishing

Srinivasan R., Parikad A, 2015. A process for value based asset management decision making. In 10th WCEAM Proceedings, Tampere, Finland

Tam, A.S.B. \& Price, J.W.H., 2008. A generic asset management framework for optimising maintenance investment decision. Production Planning \& Control, 19(4), pp.287-300.

Tsang, A.H.C., 2002. Strategic dimensions of maintenance management. Journal of Quality in Maintenance Engineering, 8(1), pp.7-39.

Wang J.Q., Chen and Parikad A., 2015. Designing performance measures for as set management systems in capital-intensive manufacturing: a case study. In 10th WCEAM proceedings, Tampere, Finland

Xu, Y., Elgh, F. \& Erkoyuncu, J., 2013. Cost Engineering for manufacturing: Current and future research. International Journal of Computer Integrated Manufacturing, pp.37-41. 